\title{
US agencies 'can fight' declining budgets
}

Washington. US science agencies will be able to win larger budgets in future years than existing projections suggest, officials of the Clinton administration told a congressional hearing investigating the impact of the projections.

Dan Goldin, the administrator of the National Aeronautics and Space Administration (NASA), told the hearing that he believed that President Bill Clinton had "empowered" him to "go into the Office of Management and Budget (OMB) and fight" for more than the projections.

These would cut NASA funding from $\$ 13.9$ billion this year to $\$ 11.6$ billion by 2000. The OMB is the powerful branch of the administration that compiles the president's annual budget proposal.

Goldin and other agency heads were brought before the Science Committee of the House of Representatives on 24 July for a long-delayed and politically charged hearing (see Nature 382, 7; 1996). The committee chairman, Robert Walker (Republican,

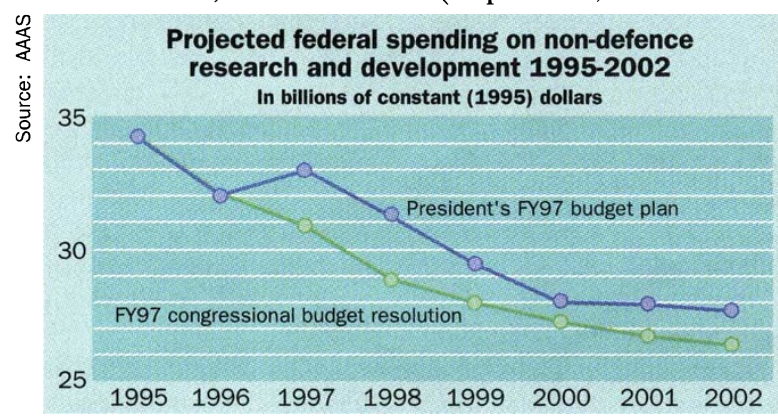

Pennsylvania), sought to prove that the administration was guilty of dishonest budgeting. Neal Lane, director of the National Science Foundation (NSF), and Martha Krebs, director of the Office of Energy Research at the Department of Energy, also testified.

Walker believes that the Republicans who control Congress have been unfairly attacked for planning to cut science budgets over the next six years, while the Clinton administration is projecting cuts almost as deep. He criticized the three officials for "going around the country attacking the Republicans' budget plan" and arguing that Clinton's own long-term plan does not matter.

The administration and Congress have published rival plans to balance the federal budget by 2002 . According to an assessment by the American Association for the Advancement of Science (AAAS), both plans imply deep cuts in spending on research and development (see figure, below left).

At a hearing of the Science Committee the day before, Al Teich, an AAAS budget analyst, acknowledged that "out-year projections [those projecting more than two years ahead] have not been reliable" in previous years. But he testified that "they are worth our attention because they tell us about the problems we face and the choices we will have to make".

Comparing the two plans,
Teich said that, in general, NASA and the NSF were ahead in the congressional plan while the energy and commerce departments did better under Clinton's. Teich added that research and development "has consistently averaged about 14 per cent of all discretionary spending" and that this was likely to remain the case. Both plans would cut discretionary spending by one-fifth by 2002.

Senator Kit Bond (Republican, Missouri), who chairs the appropriations subcommittee that funds NASA and NSF, testified that one of the space agency's main areas of activity "would have to go" under the Clinton plan. That could mean axing the space station, the shuttle, the Mission to Planet Earth, or space science.

But Goldin said: "I don't believe it makes sense to cut back on programmes based on anticipated problems. OMB expects us to fight [for more money] and OMB will not be disappointed."

George Brown (California), the senior Democrat on the committee, said that "both budgets would continue a steep decline" in US research spending as a percentage of gross national product. He added: "That is abysmal and reprehensible."

But Harold Volkmer (Missouri), another senior Democrat, defended Clinton's commitment to a balanced budget. He accused Walker of conducting "a witchhunt" and of using the committee for party-political ends "to make the president look bad".

Colin Macilwain

\section{Internet mentors seek to bring more women into science}

Boston. Plans to launch a nationwide science 'mentoring' programme for women students, using electronic mail and the Internet, are to be discussed next week at a meeting of representatives of leading US universities and colleges.

The programme would be based on a successful one-year pilot demonstration at Dartmouth College in New Hampshire. Dartmouth's 'E-mentoring' project links female students with mentors, almost all of whom are women employed in sciencerelated industries.

The intention is to devise a plan to expand the project to include 100 universities and 5,000 students over a five-year period from autumn 1997. Colleges to be represented at next week's meeting in Boston include Dartmouth, Carnegie Mellon, Cornell, Purdue, Stevens Institute of Technology, and the Universities of Washington, Michigan, and California at Berkeley.

According to Mary Pavone, director of the Women in Science Programme at Dartmouth, the approach "works particularly well for this school, given our remote location and the fact that our entire campus is networked". She adds: "We have a student culture based largely on e-mail communications." E-mail, says Pavone, is an economical, convenient and nonintrusive method for students to correspond with their mentors, offering an easy way to bridge the gap between the different lifestyles and schedules of students and working professionals.

In the Dartmouth programme, 35 science or engineering students were assigned mentors, who offered them advice about choosing courses or finding a job, as well as providing encouragement to persist in science and engineering. Through these interactions, Pavone says, "students gain a perspective they couldn't get by talking to a faculty member, parent or friend".

Carol Muller, associate dean of engineering at Dartmouth, claims: "The reinforcement that students get from outside the university can be as important, or more important, than what they get from inside the university. This programme offers them outside encouragement and support." She says that 60 per cent of graduates in science and engineering go on to work in industry.

The motivation to expand the programme stems from the fact that female students are "under-represented" in physical and quantitative sciences, and particularly in engineering, explains Muller, who is leading the initiative. Pavone cites recent US figures showing that women comprise 16 per cent of the people working in science and just 8 per cent in engineering. This imbalance, she says, is due to "subtle and not-so-subtle forms of discrimination, as well as early socialization".

A nationwide 'E-mentoring' programme would be administered by the Women in Engineering Program Advocates Network. The organization's president, Suzanne Brainard, director of the Women in Engineering programme at the University of Washington in Seattle, says a national programme could have an "enormous" impact.

The Alfred P. Sloan Foundation has provided a grant to support the planning process for establishing a national programme.

Steve Nadis 